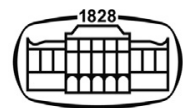

AKADÉMIAI KIADÓ

\title{
Entity encounters and the therapeutic effect of the psychedelic mystical experience
}

\author{
ANNA LUTKAJTIS* 우
}

Journal of Psychedelic Studies

4 (2020) 3, 171-178

DOI:

$10.1556 / 2054.2020 .00143$

(c) 2020 The Author(s)

RESEARCH ARTICLE

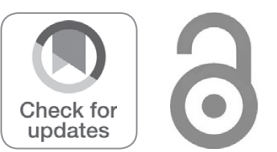

*Corresponding author.

E-mail: anna.lutkajtis@sydney.edu.au
The University of Sydney, Sydney, Australia

Received: May 21, 2020 • Accepted: August 3, 2020

Published online: November 11, 2020

\begin{abstract}
Research suggests that the clinical and therapeutic effects of psychedelics are related to their ability to induce a mystical-type experience. One particularly interesting feature of the psychedelic mystical experience is the entity encounter - people who take psychedelics sometimes describe meetings with seemingly autonomous entities which appear to possess intelligence and agency. While there has been little empirical research into psychedelic entity phenomena, qualitative studies and anecdotal reports suggest that entity encounters can have profound and lasting positive after-effects. Based on the existing data, this article argues that there is value in exploring the therapeutic potential of psychedelic entity encounters. Specifically, it proposes three possible ways that entity encounters might mediate the therapeutic effect of the psychedelic mystical experience.
\end{abstract}

\section{KEYWORDS}

psychedelics, mystical experience, entity, entities, psychology, religion

\section{INTRODUCTION: ENTITY ENCOUNTERS AND THE PSYCHEDELIC MYSTICAL EXPERIENCE}

The 'psychedelic experience' is a temporary altered state of consciousness induced by a psychedelic compound. While psychedelic altered states are highly specific to particular compounds, and the range of subjective effects that people experience is wide, there are certain features of the psychedelic experience that occur for most people. These include significant changes in perception, emotion and cognition. Additionally, when 'set' (an individual's state of mind and expectations) and 'setting' (the context in which the psychedelic is taken) are controlled for, such as in clinical trials, psychedelics have been found to reliably induce mystical-type experiences (e.g. Griffiths et al., 2018). The phenomenology of the psychedelic mystical experience, particularly as described in clinical studies, aligns with descriptions of classic 'introvertive' mystical-type experiences as described by Western scholars such as William James (2004 [1902], pp. 329-330), Walter Stace (1960) and Ralph Hood (1975). For example, the 'mystical experience questionnaire' (MEQ), a self-report measure that has been used to assess the effects of psychedelics in research studies, measures six components of the psychedelic induced mystical experience, including a sense of unity or oneness; transcendence of time and space; deeply felt positive mood; sense of awesomeness, reverence and wonder; meaningfulness of psychological or philosophical insight; and ineffability and paradoxicality (Pahnke \& Richards, 1966; Roseman, Nutt, \& Carhart-Harris, 2018). Currently, most clinical research on psychedelics has focused on these more abstract or introvertive phenomenological features of the psychedelic mystical experience (Stace, 1960).

Psychedelic mystical experiences may also contain 'extrovertive' phenomenological content; that is, sense-perceptual, somatosensory, or introspective mystical content (e.g. Marshall, 2005; Stace, 1960). One particularly interesting extrovertive feature of the psychedelic experience is the entity encounter experience. People who take psychedelics sometimes describe meetings with seemingly autonomous entities which appear to possess intelligence and agency, and are commonly described as 'beings,' 'guides,' 'spirits,' 'aliens,' 'helpers,' 'angels,' 'elves,' and 'plant spirits' (among other terms; see Davis et al., 2020; Shanon, 2010, p. 121-122). Entities are 
frequently felt to be supremely powerful, wise and loving (Luke, 2017, p. 94) and encounters are often accompanied by positive emotions such as joy, trust, surprise, love, kindness and friendship (although fear is also a common emotion associated with entity encounters) (Davis et al., 2020). While not a focus of modern Western mysticism (e.g. Hood, 1975; Stace, 1960), entity encounters have been described in a variety of spiritual and religious traditions (e.g. angel encounters in Jewish mysticism; Elior, 2004; Swartz, 1994; entity encounters in the African Bwiti religion; Kohek, Ohren, Hornby, AlcázarCórcoles, \& Bouso, 2020), and feature in shamanic cosmologies. For example, shamanic healing practices, which sometimes include the use of psychedelics, involve the alteration of consciousness in order to develop relations with a spirit world (e.g. Metzner, 1998; Winkelman, 2010, p. 204). Such practices are based on a worldview that assumes the existence of spirit beings.

Psychedelic entity encounters have been reported with high doses of intravenous or smoked N,N-dimethyltryptamine (DMT) (Strassman, 2001; Tramacchi, 2006), ayahuasca (Shanon, 2010), psilocybin (Letcher, forthcoming), and other psychedelics. Some survey data on entity prevalence with various psychedelics is available in Luke and Kittenis (2005, p. 314), who note that entity contact experiences are widespread with the use of DMT and relatively widespread with ayahuasca. There is only a very small amount of empirical research that looks at psychedelic entity phenomena (e.g. Davis et al., 2020; Strassman, 2001), however entity encounters have been described in some qualitative studies (Cott \& Rock, 2008; Gaia, 2016; Heuser, 2006; Shanon, 2010; Tramacchi, 2006), numerous anecdotal online reports (Meyer, 2006; dmt-nexus.me; erowid.org; shroomery.org), in psychedelic autobiographies (e.g. Khan, 2017), and in podcast interviews with psychonauts (e.g. psychedelicstoday.com; psychedelictimes.com; jameswjesso. com/podcast). Psychedelic entities are also commonly depicted in psychedelic and visionary art (e.g. the work of Pablo Amaringo, Luke Brown and many others).

There are numerous interpretations of psychedelic entity phenomena and a detailed consideration of the ontology of entity experiences is beyond the scope of this article. However, it is significant to note that regardless of their ontology, entity experiences have been reported to feel "more real than normal reality" both during (81\%) and after (65\%) the encounter (Davis et al., 2020, p. 5). For example, in their survey study of entity encounter experiences $(n=2,561)$, Davis et al. (2020, p. 5) report:

From their current perspective, three-quarters of respondents reported that the entity existed in some real but different dimension or reality $(49 \%)$ or in a combination of some real but different dimension or reality and in normal everyday physical reality (26\%). A minority of respondents (9\%) reported that the entity existed "completely within myself," or that the entity existed only in normal reality (1\%). Most respondents (72\%) endorsed believing that the entity continued to exist after their encounter, and that the experience altered the respondent's fundamental conception of reality $(80 \%)$.

\section{THE MYSTICAL EXPERIENCE AND THERAPEUTIC EFFECTS}

Both mystical experiences (regardless of their cause) and psychedelic entity encounters are reported to have profound and sometimes lasting after-effects. Many scholars have described the positive after-effects that follow mystical experiences. For example, Wulff (2014, p. 375) writes:

\begin{abstract}
Although a profound sense of fatigue may immediately follow a mystical experience, and the knowledge or insight that defines it proves impossible to recapture, there remains the joyful impression of having encountered a higher reality and discovered new truths. Ordinary concerns recede in importance or appear in a new light, and new beliefs and values take the place of old ones. Some experients report feeling an intensified love and compassion for others, and many say that life as a whole has taken on new meaning.
\end{abstract}

Similar after-effects occur with psychedelic occasioned mystical experiences. For example, in the classic 'Good Friday' psilocybin study by Pahnke (1966), participants who had mystical-like experiences recounted significantly more enduring positive changes in their attitudes and behaviour (towards self, others, life, and the psychedelic experience itself) than those in the control group. In a long-term followup to this study, Doblin (1991, p. 25) interviewed seven participants from the original study and found "a substantial amount of persisting positive effects and no significant longterm negative effects." The psilocybin occasioned mystical experience has also been associated with beneficial changes including enduring trait-level increases in prosocial attitudes and behaviours (Griffiths et al., 2018), and increases in the personality domain of openness (MacLean, Johnson, \& Griffiths, 2011). In clinical studies, the psychedelic mystical experience has been associated with positive treatment outcomes for conditions including treatment-resistant depression (Roseman et al., 2018), and anxiety and depression related to advanced stage cancer (Nutt, 2016).

Psychedelic mystical experiences can also be powerful enough to cause significant changes to beliefs and worldviews. A recent study by Griffiths, Hurwitz, Davis, Johnson, and Jesse (2019) found that self-identified atheism significantly decreased among people who had mystical or "God encounter experiences" occasioned by classic psychedelics. Davis et al. (2020) described a similar effect with psychedelic entity encounter experiences in that more than half of those who identified as atheist before the experience no longer identified as atheist afterwards. Additionally, the authors found that entity experiences were rated as "among the most meaningful, spiritual, and psychologically insightful lifetime experiences, with persisting positive changes in life satisfaction, purpose, and meaning attributed to the experiences" (Davis et al., 2020, p. 1). Similarly, in a study by Griffiths et al. (2011), 83\% of participants who had a psilocybin occasioned mystical experience rated it as the single most, or among the five most, spiritually significant experiences of their life. 


\section{COULD ENTITY ENCOUNTERS MEDIATE THE THERAPEUTIC EFFECT OF THE PSYCHEDELIC MYSTICAL EXPERIENCE?}

So far, the exact therapeutic mechanisms behind the psychedelic mystical experience are unknown. Carhart-Harris and Friston (2019) propose an "entropic brain hypothesis" whereby the therapeutic effect of psychedelics might be explained partly by their ability to allow the 'relaxation' and revision of prior beliefs. Additionally, a study by Watts, Day, Krzanowski, Nutt, and Carhart-Harris (2017) found that psilocybin treatment for depression may work via two psychological change processes: a change from disconnection (from self, others, and world) to connection, and from avoidance (of emotion) to acceptance. Currently no empirical studies have examined a possible connection between entity encounters and the psychotherapeutic effect of the psychedelic mystical experience. To paraphrase Luke (2017, p. 102), when it comes to entity encounters it seems that all we have to rely on is anecdote and phenomenology. Anecdotal entity encounter reports are numerous and an exhaustive analysis of these reports is obviously beyond the scope of this article. However, a preliminary review of encounter experiences based on existing anecdotal testimonies and phenomenological studies, does reveal a potential link between the entity encounter experience and healing. Some emergent themes are now discussed.

\section{Personal and transpersonal insight}

A frequently reported characteristic of the entity encounter is the transmission of information. Anecdotal and phenomenological accounts of entity encounters commonly describe communication events where entities answer questions or volunteer information. Communication with entities can involve the use of language, music, telepathy, or somehow 'just knowing' the intention of the entity. For example, in the Davis et al. (2020) survey study more than two thirds of respondents (69\%) endorsed receiving a message, task, mission, purpose, or insight from the entity encounter experience. In $85 \%$ of encounters, extrasensory (i.e. telepathic) senses were reported to be involved in the interaction. The authors performed a qualitative analysis of the data which revealed that $22 \%$ of the responses concerned a personal insight into the subject's behaviours, emotions, relationships, or life's path. Similarly, Heuser (2006, p. 68) conducted a thematic analysis of ayahuasca entity encounters and found that:

non-human entities were at times found to express human emotions of love and concern for human welfare. Entities sometimes guided reporters to clarity and integration, which was often attained after contemplating difficult problems or dark themes.

These findings align with recent research that suggests that psychological insight is associated with the therapeutic effect of psychedelic experiences (e.g. Belser et al., 2017;
Gasser, Kirchner, \& Passie, 2015) and Davis et al. (2020, p. 11) posit that "the frequent reporting of psychological insights occasioned by these entity encounters suggests that such experiences may have therapeutic potential."

In his comprehensive cognitive psychological study of ayahuasca, Shanon (2010, p. 143) found that some of the most essential themes of ayahuasca visions were related to psychological understanding. In an ayahuasca vision, psychological insight may come from re-visiting the past, reliving situations of conflict or trauma, or meetings with significant others that result in a new perspective on the relationship. In his study of ayahuasca, Heuser (2006, p. 70) also reported that entities sometimes engaged subjects in "biographical recapitulation" - a process which involves the viewing of snapshots and scenes from one's personal autobiographical past: "I found this in relation to entities who sometimes revealed unknown, repressed, or forgotten biographical events, or who facilitated increased integration of biographical material in some way." Carhart-Harris et al. (2012) note that there are several reports in the psychiatric literature of spontaneous autobiographical recollections or 'relivings' occasioned by psychedelics, and that part of the therapeutic action of psilocybin may be related to its ability to allow people to address rather than suppress or avoid difficult memories and emotions (Carhart-Harris \& Goodwin, 2017). It is possible that entity encounters mediate this effect.

Information provided by entities may also be of a transpersonal nature. For example, Luke (2017, p. 95) writes that DMT entities may "impart insightful information about themselves and the universe in which they were inhabited." Similarly, a phenomenological study by Cott and Rock (2008, p. 366) found that participants who took DMT regularly gained insight into both themselves and the "nature of reality," and that these insights were retained and assimilated into users' lives after the DMT experience. One participant in their study gave an account of gaining metaphysical insights and knowledge pertaining to the structure of the universe: "All I remember is I was shown how our physical three dimentional [sic] reality fits into the reality of the bigger universe that lies behind our three dimentional [sic] universe" (Cott \& Rock, 2008, p. 366). A similar experience was described by an informant in Heuser's (2006, p. 56) study who related: "I then was given the understanding that all life, all we know, all I am, is energy, this energy is timeless and will continue on. I knew now the reality of this time and space is just something my energy has chosen to reside in for now." Heuser's data suggests that when entities are associated with transpersonal noetic states they tend to appear in the role of a guide (who aids the transition to sources of special knowledge) or a guardian (who blocks the way, seemingly as a test). While questions obviously remain regarding the accuracy or reliability of such information, it appears that transpersonal messages often provide a sense of comfort or reassurance for the receiver.

${ }^{1}$ Shanon $(2010$, pp. 114; 143) also describes visions that specifically involve biographical memory. 
Entities may also deliver knowledge or insight regarding death. For example, in Davis et al.'s (2020, p. 8) survey study 168 respondents $(7 \%)$ reported that the message received from their entity encounter included themes about death, the afterlife, the pre-birth state or reincarnation. Comments from respondents included "There was insight that death is not the end" and "That death is just the beginning of another greater universe." Interestingly, when considered psychometrically, the DMT 'breakthrough experience,' in which entities are extremely prevalent (e.g. in controlled studies, 50+\% Strassman, 2001; 75\% Timmermann, 2017; 95\% Luke, 2019), is largely indistinguishable from the neardeath experience (NDE) (Timmerman et al., 2018). The NDE also commonly features encounters with entities and is reported to have profound and long lasting beneficial aftereffects, including reductions in death anxiety, increased appreciation for nature, pro-ecological behaviour, significant clinical improvements in depression, and increased selfworth (for a review, see Greyson, 2014; Timmerman et al., 2018).

These findings align with empirical studies that report decreases in death-related fear and anxiety after psychedelic use. For example, Griffiths et al.'s (2019) survey study of subjective "God encounter experiences" found that a decreased fear of death was a persisting after-effect among respondents. Similarly, in clinical studies psilocybin has been shown to decrease death anxiety, and this effect is mediated by the psilocybin occasioned mystical experience (Griffiths et al., 2016). Moreton, Szalla, Menzies, and Arena (2020) also posit that reduced death anxiety may be a mediator of the therapeutic effects of psychedelics and propose several mechanisms that might underly this effect.

\section{Encounters with the divine}

Psychedelic mystical experiences frequently involve encounters with God or 'the Divine.' In the case of ayahuasca, Shanon (2010, p. 155) writes that these types of visionary experiences are especially powerful:

\begin{abstract}
Encounters with the Divine are usually accompanied by various insights regarding God and his relationships with both nature and humanity. Several informants underlined their appreciation that the Divine exhibits a great sense of humour. With this, things are seen in a perspective different from the regular human one which is conceived to be small and limited in comparison ... often the experience of divine presence is associated with the appreciation of the bounty of life and the harmony of the universe.
\end{abstract}

Similarly, in his phenomenological investigation of DMT, Tramacchi (2006, p. 93) reports an example of contact with the Divine which led to transformation and healing:

A sense of having received divine grace through DMT is not uncommon and feelings of gratitude can be enduring, as for example, in the following testimony of a 46 year old male respondent [25]: "I return healed, I receive gnosis, healing, inspiration ... A spiritual gift. Cosmic fortune to see the truth before I deserved it. Thanks Universe", the same informant also stated the following soteriological doctrine: "The plants want to save us from misery and take us to mystery."

Encounters with divine entities, such as angels or other celestial beings, may induce strong feelings of wonder and awe. The following is an account of an encounter with 'angels' after ingesting psilocybin-containing mushrooms (Letcher, forthcoming):

I'm not into angels or any of that stuff. But these beings I encountered, I think they're fucking angels [laughs]. They were so immense and awe-inspiring and terrifying and powerful ... you can't explain it ... [they had] ninety thousand million facets to them and then one point they'd be grotesque with like these hundreds of tongues and mouths and eyes and then they'd just grow these god heads and I kind of experienced them as vortexes of deep power, divine vortexes of energy and ... the only model that I could ascribe to them was an angelic being ... they were quite terrifying but it was so beautiful as well and I felt deeply honoured ... a touch of the gods ...

Similarly, Khan (2017, p. 337) describes an awe-inducing encounter with a DMT entity:

The huge portion of entity that remained continued to gaze down upon me and I could feel the terrific weight of its otherworldly stare. I felt there was simply nothing I could do that would properly convey my recognition, my respect and awe for that which had just revealed itself to me.

Recent research from psychology suggests that the experience of awe - the feeling evoked by being in the presence of something vast that transcends current frames of reference - can have beneficial effects on wellbeing (e.g. Anderson, Monroy, \& Keltner, 2018; Rudd, Vohs, \& Aaker, 2012). This is not surprising given that awe commonly involves positive feelings of wonder and amazement. However, perhaps more interestingly, evidence suggests that awe can also significantly alter the self-concept by triggering a sense of 'smallness' of the self in relation to the environment and the greater world (Piff, Dietze, Feinberg, Stancato, \& Keltner, 2015). Awe-induced diminishment of the 'small' self may then shift attention away from individual interests and personal day-to-day concerns (Shiota, Keltner, \& Mossman, 2017). While research on awe is a relatively new area (awe was largely ignored by psychologists until the early 2000s), these studies suggest a possible mechanism by which entity encounter experiences may mediate the therapeutic effect of the psychedelic mystical experience. Another possible mechanism is proposed by Davis et al. (2020), who posit that the sudden ontological shift (i.e. 'ontological shock') associated with DMT occasioned entity experiences may increase psychological flexibility which, in turn, may mediate positive changes in attitudes, mood and behaviour.

\section{'Magic operations'}

Perhaps most mysteriously, psychedelic entities are said to be able to physically interact with subjects. Specifically, entities may perform actions on an experiencer's body; actions 
that sometimes lead to discernable after-effects. Shanon (2010, p. 101) describes a form of passive interaction with entities whereby: "drinkers of ayahuasca often feel that they are being enticed or lured by creatures or entities that attempt to touch them." One example of a passive interaction is the act of performing a 'magic operation' or 'psychic surgery.' Shannon (2010, p. 101) states that he has been operated on by entities on four separate occasions, and relates one: "I was lying down and a colourful weblike drape or mantle was stretched over me, as a spell. One person was in charge of the operation and others were watching, making sure that nothing bad would happen to me." Similarly, in his autobiographical account of DMT use, Khan (2017) describes numerous instances of being operated on by entities. Tramacchi (2006, p. 93) also notes that about one sixth of the DMT accounts he collected contained elements suggestive of "shamanic ordeal," including "the modification of the subject's internal organs through surgical interventions performed by spirits."

'Magic operations' or surgery-type experiences were also recounted by volunteers in Strassman's (2001) clinical study in which he injected sixty volunteers with DMT. Strassman (2001, p. 199) reported "surprising and remarkable consistencies” among participants' experiences of entity contact encounters:

Volunteers find themselves on a bed or in a landing bay, research environment, or high-technology room. The highly intelligent beings of this "other" world are interested in the subject, seemingly ready for his or her arrival and waste no time in "getting to work" ... Their "business" appeared to be testing, examining, probing, and even modifying the volunteer's mind and body ... The purpose of contact was uncertain, but several subjects felt a benevolent attempt on the beings' part to improve us individually or as a race.

Surgery may involve the implanting of an object inside the subject's body. Heuser (2006, p. 72) describes the example of one informant who, during an ayahuasca entity encounter:

received a clutch of octopus eggs that were laid inside his head. He interpreted this as an auspicious occasion, and wrote that he believed the eggs symbolized a source of wisdom. He recognized the octopus as a benign ally "right away."

A separate informant in the same study related having an object placed inside her head:

The Ayahuasca honoured my request to be dismembered. Maggots consumed all my flesh before I was given a variety of new improved body parts and had the top of my head opened up a book of plant knowledge placed inside for future reference and then my head closed up again (Heuser, 2006, pp. 108-109).

Examples of surgical interventions leading to directly observable after-effects, such as obvious relief from physical symptoms, are less common but they do exist. For example, Shanon (2010, p. 147) describes the experience of an informant who was in physical agony after being stung by two wasps. He was seemingly cured after an ayahuasca entity encounter: "I saw two beautiful women who sucked the wasp poison out of the two sides of my nose. They passed it to my mouth and told me to spit. I did this and was, in reality, cured." In her phenomenological study of 'changa' (a DMT/ MAOI-infused smoking blend) Gaia (2016, p. 62) also cites an example of an entity encounter that resulted in an observable physical change. Her informant, Fredo "became convinced that some alien intelligence had reprogrammed him during a changa session and that since this occasion his auditory capacity had increased. Fredo's career as a music producer suddenly sped-up and evolved."

In Western psychology and medicine, such outcomes would be described as a placebo effect, however the belief that healing in another dimension can lead to tangible effects in the physical plane is characteristic of shamanic and neoshamanic experience. Gaia (2016, p. 54) reports that within her respondents' narrations, such neo-shamanic experiences were often interpreted as involving a "DIY connection with an astral plane" which resulted in self-healing or personal transformation. Parallels can also be drawn between psychedelic surgery experiences and Brazilian faith healing. For example, in her ethnographic account of the John of God movement, Rocha (2017, p. 105) explains some of the movement's healing practices (which include psychic surgery performed by spiritual entities) in terms of a radical experience of the sacred which allows people to - paradoxically - feel empowered by surrendering to a "higher power." This close connection between spirituality and healing (something that has been lost in mainstream psychology and biomedicine) allows people to transform their narrative of illness from "chaos" to "quest" and eventually "restitution" (Rocha, 2017, p. 105).

\section{Challenging experiences with entities}

Challenging experiences with psychedelics (colloquially referred to as 'bad trips') can involve intense negative feelings (such as anxiety, panic, fear, paranoia, disorientation, etc.) and sometimes a fear that one is dying or going insane (Garcia-Romeu \& Richards, 2018, p. 302). Challenging experiences have been reported with psychedelic entity encounters. In the Davis et al. (2020) survey study, $41 \%$ of respondents reported fear and 19\% reported feelings of disgust during the encounter, although the authors note that these emotions were almost never reported to be the most prominent emotion during the experience. Davis et al. (2020, p. 10) observe that the experience of negative emotions during the entity encounter is consistent with the finding that $32 \%$ of respondents rated the experience to be among the five most psychologically challenging experiences of their lifetime. Heuser (2006) also reports that fear was frequently associated with entity encounters during ayahuasca experiences; sometimes entities were reassuring presences to counteract fear, and sometimes fear was related to the entities themselves who could be "terrifying in their otherness" and possess "a menacing quality" (Heuser, 2006, p. 67). Gaia (2016) notes that in her study, changa visions 
were frequently narrativised as a mysterium tremendum et fascinans - a mystery that is both fearful and fascinating. Such descriptions align with Rudolf Otto's (1869-1937) concept of the 'numinous' as a mystical experience that is both terrifying and awe-inspiring (Otto, 1950 [1923]).

Scholars have argued that challenging psychedelic experiences should not necessarily be devalued as they can, when skillfully managed, lead to insight and therapeutic benefits (e.g. Carbonaro et al., 2016; Garcia-Romeu \& Richards, 2018, p. 303). This idea is supported by Heuser (2006, p. 81), whose informants related accounts of entities appearing "just at the precise moment of greatest tension, just before intense fear gave way to breakthroughs to clarity, joy, and the other higher emotional states." Similarly, Davis et al. (2020, p. 10) suggest that psychedelic entity encounters may be comparable to alien abduction experiences, which are often initially frightening and confusing but later on "may become valued as experiences of transformation or spiritual growth." While there is some preliminary data to support the idea that challenging entity experiences may be therapeutic, more research is needed in order to better understand the nature of the psychedelic entity experience and how it might relate to therapeutic effects. Additionally, while some degree of fear may simply be inherent to the entity encounter, future studies might also explore whether it is possible to minimize extremely negative experiences by paying careful attention to pre-existing psychological traits, 'set,' and 'setting.'

\section{CONCLUSION: A ROLE FOR PSYCHEDELIC ENTITIES IN WESTERN PSYCHOTHERAPY?}

While the psychedelic mystical experience is reported to be a major factor mediating the efficacy of psychedelic therapy, the mechanisms underlying the therapeutic effect of the mystical experience are still largely unknown. Empirical studies of psychedelics have focused on the more abstract or introvertive phenomenological features of the psychedelic occasioned mystical experience, however there is some preliminary evidence to suggest that entity encounters could also mediate the therapeutic and healing effects of psychedelics. Details of entity encounters and the meanings attributed to such experiences vary widely (e.g. Davis et al., 2020) and this article has only delineated three themes related to entities and their potential therapeutic effects, hence there is much left to explore. This article has also suggested some initial ideas regarding possible therapeutic mechanisms, however future research might investigate these potential mechanisms in more detail, and also consider theory from evolutionary psychology and the cognitive science of religion (e.g. Winkelman, 2018). A more comprehensive consideration of religions and healing traditions that involve entities (e.g. shamanism; faith healing) might provide further insight into the relationship between otherworldly entities and healing. This article has also pointed out that not all entity encounters are wholly positive, and many are reported to be frightening and psychologically challenging. Future research might examine how contextual factors such as individual psychological traits, and 'set' and 'setting,' influence the valence of the entity encounter experience.

Given the growing interest in psychedelic-based interventions and the probability that psychedelics (in particular, psilocybin) will soon be utilised as a mainstream mental health treatment, clinicians are likely to be faced with an interesting situation: patients who have mystical experiences - and possibly entity encounters - induced by their psychotherapeutic treatment. How will psychiatry and psychology approach this in clinical practice? Traditionally, these disciplines have viewed religion, spirituality, mysticism and altered states of consciousness as symptoms of mental illness, rather than paths to mental wellness. In psychiatry, mystical experiences have generally been ignored or conflated with psychopathology (e.g. William James' 'diabolical mysticism'; James, 2004 [1902]). Further, 'religious delusions' are reported to be prevalent in adult patients with schizophrenia (5\%-44\%) and psychotic depression (6\%$14 \%$ ) (Noort, Beekman, van Gool, \& Braam, 2018) and encounters with anomalous entities that others cannot see are generally categorised as visual hallucinations (e.g. Blom, 2013). Additionally, with patients experiencing psychosis, a common approach in psychiatry has been to not encourage the patient to talk about their symptoms in order to avoid inadvertent collusion regarding delusions (McCabe \& Priebe, 2008). Hence up until now, discussions of religion and spirituality have largely been avoided in clinical practice (e.g. Pargament, Mahoney, Shafranske, Exline, \& Jones, 2013), however given the overt mystical nature of the psychedelic experience and its potential future use in psychotherapy, this approach seems unlikely to be able to continue.

Finally, more research is needed into the unique phenomenology of the psychedelic occasioned mystical experience, psychedelic entity encounters, and the meanings attributed to these experiences. Clearly the psychedelic mystical experience has features that do not fit neatly into the classic introvertive definitions of mysticism that have been favoured by Western psychology. Future research into the extrovertive features of the psychedelic mystical experience, such as entity encounters, should inform future medical studies and clinical trials and possibly provide more insight into how psychedelics have their therapeutic effect. Regardless of whether psychedelic mystical phenomena such as entities are ontologically 'real,' these experiences do have real and meaningful consequences and deserve the attention of researchers.

\section{REFERENCES}

Amaringo, P. website: https://pablo-amaringo.pixels.com/. Accessed May 2020.

Anderson, C. L., Monroy, M., \& Keltner, D. (2018). Awe in nature heals: Evidence from military veterans, at-risk youth, and college students. Emotion, 18(8), 1195-1202. 
Belser Alex, B., Agin-Liebes, G., Swift, T. C., Terrana, S., Devenot, N., Friedman, H. L., (2017). Patient experiences of psilocybinassisted psychotherapy: An interpretative phenomenological analysis. Journal of Humanistic Psychology, 57(4), 354-388.

Blom, J. D. (2013). Hallucinations and other sensory deceptions in psychiatric disorders. In R. Jardri, A. Cachia, \& P. Thomas (Eds.), The neuroscience of hallucinations. New York, NY: Springer.

Brown, L. website: https://www.lukebrownart.com/. Accessed May 2020.

Carbonaro, T. M., Bradstreet, M. P., Barrett, F. S., MacLean, K. A., Jesse, R., Johnson, M. W., (2016). Survey study of challenging experiences after ingesting psilocybin mushrooms: Acute and enduring positive and negative consequences. Journal of Psychopharmacology, 30(12), 1268-1278.

Carhart-Harris, R. L., \& Friston, K. J. (2019). REBUS and the anarchic brain: Toward a unified model of the brain action of psychedelics. Pharmacological Reviews, 71, 316-344.

Carhart-Harris, R. L., \& Goodwin, G. M. (2017). The therapeutic potential of psychedelic drugs: Past, present, and future. Neuropsychopharmacology, 42, 2105-2113.

Carhart-Harris, R. L., Leech, R., Williams, T. M, Erritzoe, D., Abbasi, N., Bargiotas, T., (2012). Implications for psychedelic-assisted psychotherapy: Functional magnetic resonance imaging study with psilocybin. The British Journal of Psychiatry, 200, 238-244.

Cott, C., \& Rock, A. (2008). Phenomenology of N,N-dimethyltryptamine use: A thematic analysis. Journal of Scientific Exploration, 22(3), 359-370.

Davis, A. K., Clifton, J. M., Weaver, E. G., Hurwitz, E. S., Johnson, M. W., \& Griffiths, R. R. (2020). Survey of entity encounter experiences occasioned by inhaled N,N-dimethyltryptamine: Phenomenology, interpretation, and enduring effects. Journal of Psychopharmacology, 34(9), 1008-1020.

Doblin, R. (1991). Pahnke's "good friday experiment": A long-term follow-up and methodological critique. Journal of Transpersonal Psychology, 23(1), 1-28.

Elior, R. (2004). Three temples: On the emergence of Jewish mysticism. Portland, OR: Oxford.

Gaia, G. (2016). Changa's Alchemy: Narratives of transformation in psychedelic experiences, Masters Thesis. Amsterdam, Netherlands: University of Amsterdam.

Garcia-Romeu, A., \& Richards, W. A. (2018). Current perspectives on psychedelic therapy: Use of serotonergic hallucinogens in clinical interventions. International Review of Psychiatry, 30(4), 291-316.

Gasser, P., Kirchner, K., \& Passie, T. (2015). LSD-assisted psychotherapy for anxiety associated with a life-threatening disease: A qualitative study of acute and sustained subjective effects. Journal of Psychopharmacology, 29(1), 57-68.

Greyson, B. (2014). Near-death experiences. In E. Cardeña, , S. J. Lynn, , \& S. Krippner, (Eds.), Varieties of anomalous experience: Examining the Scientific evidence (pp. 333-367). Washington, DC: American Psychological Association.

Griffiths, R. R., Hurwitz, E. S., Davis, A. K., Johnson, M. W., \& Jesse, R. (2019). Survey of subjective "god encounter experiences": comparisons among naturally occurring experiences and those occasioned by the classic psychedelics psilocybin, LSD, Ayahuasca, or DMT. Plos One, 14(4).
Griffiths, R. R., Johnson, M. W., Carducci, M. A., Umbricht, A., Richards, W. A., Richards, B. D., (2016). Psilocybin produces substantial and sustained decreases in depression and anxiety in patients with life-threatening cancer: A randomized doubleblind trial. Journal of Psychopharmacology, 30(12), 1181-1197.

Griffiths, R. R., Johnson, M. W., Richards, W. A., Richards, B. D., Jesse, R., MacLean, K. A., (2018). Psilocybin-occasioned mysticaltype experience in combination with meditation and other spiritual practices produces enduring positive changes in psychological functioning and in trait measures of prosocial attitudes and behaviors. Journal of Psychopharmacology, 32(1), 49-69.

Griffiths, R. R., Johnson, M. W., Richards, W. A., Richards, B. D., McCann, U., Jesse, R., (2011). Psilocybin occasioned mysticaltype experiences: Immediate and persisting dose-related effects. Psychopharmacology, 218(4), 649-665.

Heuser, J. (2006). Ayahuasca entity visitations: A thematic analysis of internet-reported encounters, $\mathrm{PhD}$ Dissertation. San Francisco, CA: California Institute of Integral Studies.

Hood, R. (1975). The construction and preliminary validation of a measure of reported mystical experience. Journal for the Scientific Study of Religion, 14(1), 29-41.

James, W. (2004 [1902]). The varieties of religious experience. New York, NY: Barnes \& Noble.

Khan, D. (2017). DMT \& my occult mind II: Investigation of occult realities using the spirit molecule (book one). CreateSpace Independent Publishing Platform.

Kohek, M., Ohren, M., Hornby, P., Alcázar-Córcoles, M. Á, \& Bouso, J. C. (2020). The ibogaine experience: A qualitative study on the acute subjective effects of ibogaine. Anthropology of Consciousness, 31(1), 91-119.

Letcher, A. (forthcoming). Psychedelia britannia: Druids on drugs. In E. D. White, \& J. Woolley (Eds.), Cutting the mistletoe.

Luke, D. (2017). Otherworlds: Psychedelics and exceptional human experience. London, UK: Muswell Hill Press.

Luke, D. (2019). Hyperspatial journeys with your goods'elf: Experimental DMT field research. In Paper presented at Breaking Convention: The 5th International Conference on Psychedelic Consciousness, University of Greenwich, London, 16th-18th August 2019.

Luke, D. P., \& Kittenis, M. (2005). A preliminary survey of paranormal experiences with psychoactive drugs. Journal of Parapsychology, 69(2), 305-327.

MacLean, K. A., Johnson, M. W., \& Griffiths, R. R. (2011). Mystical experiences occasioned by the hallucinogen psilocybin lead to increases in the personality domain of openness. Journal of Psychopharmacology, 25(11), 1453-1461.

Marshall, P. (2005). Mystical encounters with the natural world: Experiences and explanations. Oxford, UK: Oxford University Press.

Mccabe, R., \& Stefan, P. (2008). Communication and psychosis: It's good to talk, but how?. The British Journal of Psychiatry, 192(6), 404-405.

Metzner, R. (1998). Hallucinogenic drugs and plants in psychotherapy and shamanism. Journal of Psychoactive Drugs: Therapeutic Use of Hallucinogens, 30(4), 333-341.

Meyer, P. (2006). Reports which attest to contact with apparently independently-existing intelligent entities within what seems to be an alternate reality. In 340 DMT trip reports. Available at: 
www.serendipity.li/dmt/340_dmt_trip_reports.htm. Accessed May 2010.

Moreton, S. G., Szalla, L., Menzies, R. E., \& Arena, A. F. (2020). Embedding existential psychology within psychedelic science: Reduced death anxiety as a mediator of the therapeutic effects of psychedelics. Psychopharmacology, 237, 21-32.

Noort, A., Beekman, A. T, van Gool, A. R, \& Braam, A. W. (2018). Religious delusions in older adults: Diagnoses, combinations, and delusional characteristics. International Journal of Geriatric Psychiatry, 33(12), 1680-1687.

Nutt, D. (2016). Psilocybin for anxiety and depression in cancer care? Lessons from the past and prospects for the future. Journal of Psychopharmacology, 30(12), 1163-1164.

Otto, R. (1950 [1923]). The idea of the holy. San Diego, CA: The Book Tree. Reprint of 2nd ed.

Pahnke, W. N. (1966). Drugs and mysticism. International Journal of Parapsychology, 8(2), 295-315.

Pahnke, W. N., \& Richards, W. A. (1966). Implications of LSD and experimental mysticism. Journal of Religion and Health, 5, 175-208.

Pargament, K., Mahoney, A., Shafranske, E. P., Exline, J. J., \& Jones, J. W. (2013). From research to practice: Toward an applied psychology of religion and spirituality. American psychological association handbook of psychology, religion and spirituality (Vol 2): An applied psychology of religion and spirituality. Washington, DC: PsycBOOKS. American Psychological Association.

Piff, K., Dietze, P., Feinberg, M., Stancato, D. M., \& Keltner, D. (2015). Awe, the small self, and prosocial behavior. Journal of Personality and Social Psychology, 108(6), 883-899.

Rocha, C. (2017). John of god: The globalization of Brazilian faith healing. New York, NY: Oxford University Press.

Roseman, L., Nutt, D. J., \& Carhart-Harris, R. (2018). Quality of acute psychedelic experience predicts therapeutic efficacy of psilocybin for treatment-resistant depression. Frontiers in Pharmacology, 8, 1-10.

Rudd, M., Vohs, K. D., \& Aaker, J. (2012). Awe expands people's perception of time, alters decision making, and enhances wellbeing. Psychological Science, 23(10), 1130-1136.
Shanon, B. (2010). The antipodes of the mind: Charting the phenomenology of the ayahuasca experience. New York, NY: Oxford University Press.

Shiota, M. N., Keltner, D., \& Mossman, A. (2007). The nature of awe: Elicitors, appraisals, and effects on self-concept. Cognition \& Emotion, 21, 944-963.

Stace, W. T. (1960). Mysticism and philosophy. London, UK: Macmillan and Co. Ltd.

Strassman, R. (2001). DMT: The spirit molecule. Rochester, Vermont: Park Street Press.

Swartz, M. D (1994). "Like the ministering angels": Ritual and purity in early jewish mysticism and magic. Association for Jewish Studies Review, 19(2), 135-168.

Timmermann, C. (2017). Dynamic transitions of consciousness: An EEG study using DMT. In Paper presented at Breaking Convention: The 5th International Conference on Psychedelic Consciousness, University of Greenwich, London, 30th June-2nd July 2017. Available at: https://www.youtube.com/watch? $\mathrm{v}=\mathrm{sZN}$ tEFQ4iF4. Accessed July 2020.

Timmermann, C., Roseman, L., Williams, L., Erritzoe, D., Martial, C., Cassol, H., (2018). DMT models the near-death experience. Frontiers in Psychology, 9, 1-12.

Tramacchi, D. (2006). Vapours and visions: Religious dimensions of DMT use, PhD Dissertation. Brisbane, QLD: The University of Queensland.

Watts, R., Day, C., Krzanowski, J., Nutt, D., \& Carhart-Harris, R. (2017). Patients' accounts of increased "connectedness" and "acceptance" after psilocybin for treatment-resistant depression. Journal of Humanistic Psychology, 57(5), 520-564.

Winkelman, M (2010). Shamanism (2nd ed.). Santa Barbara, CA: Praeger.

Winkelman, M. J. (2018). An ontology of psychedelic entity experiences in evolutionary psychology and neurophenomenology. Journal of Psychedelic Studies, 2(1), 5-23.

Wulff, D. M. (2014). Mystical experiences. In E. Cardeña, , S. J. Lynn, , \& S. Krippner, (Eds.), Varieties of anomalous experience: Examining the scientific evidence (pp. 369-408). Washington, DC: American Psychological Association. 